\title{
Hydromechanical behaviour of hydrophobised soils of varying degrees of saturation: a comprehensive review
}

\author{
Zheng Zhou, ${ }^{1, *}$, and Anthony K. Leung ${ }^{1}$ \\ ${ }^{1}$ Department of Civil and Environmental Engineering, the Hong Kong University of Science and Technology, Hong Kong SAR
}

\begin{abstract}
Artificially hydrophobised soil has been recently considered as an alternative engineering material that may be used to reduce water (or rainfall) infiltration and hence to enhance the geotechnical performance and stability of earthen structures such as slope and landfill covers. Thorough research has been conducted to study the hydrological behaviour and properties of hydrophobised soil in the last four decades. Mechanical properties of this kind of material has received some attention only since 2011 , focusing on how hydrophobisation may affect the shearing behaviour and shear strength parameters including friction angle. Knowledge on the effects of hydrophobisation on other hydromechanical properties of soil that are relevant to geotechnical engineering applications is lacking. This paper therefore aims to conduct a comprehensive review and carry out some reinterpretation of selected literature with references to existing theories or frameworks of soil mechanics. Attempts are made to generalise and highlight not only the shearing behaviour, but also dilatancy, compressibility and stiffness of hydrophobised soil. Research gaps that may be worth exploring are given after the review.
\end{abstract}

\section{Introduction}

Naturally-occurring hydrophobic soil (sometimes known as water repellent or non-wettable soil) is often found in shallow depth $(<0.5 \mathrm{~m})$ due to wildfire, liquids released from decomposition of plant litter, hydrophobic organic matter released from plant roots and waxes eroded from plant leaves [1]. The surface of is kind of soil is often coated with hydrophobic organic matters, which make the soil become low to no affinity to water. This may cause problems, such as the increase of overland flow and consequently soil erosion during rainfall and also possibly the decrease of vegetation cover [1-3].

Because of the feature of being low to no affinity to water, engineers are inspired to apply hydrophobic or hydrophobised soil as a cover to reduce water infiltration and hence enhance the stability of earthen structures such as slope and landfill covers $[4,5]$. The process of artificially making soil to be hydrophobic is called hydrophobisation-chemical reactions between a soil and a hydrophobic agent (e.g., dimethyldichlorosilane (DMDCS)) and the production of a hydrophobic coating (e.g., polydimethylsiloxane (PDMS) for the case of DMDCS; [6, 7]; see Table 1 for other agents). In this paper, soil with and without hydrophobisation are denoted as treated and untreated soil, respectively. In the literature, attempts were also made to increase soil hydrophobicity by mixing with some hydrophobic agents (e.g. polytetrafluoroethylene (PTFE) [8]). The scope of this paper is limited to the review of the engineering behaviour of artificially and chemically hydrophobised soil, which are mainly found in existing literature.

Extensive studies have been carried out to quantify some hydrological properties of hydrophobised soil such as water retention [9] and infiltrability [10]. In addition to element tests, flume tests have also been carried out to

Table 1. A summary of reviewed references which examined the hydromechanical properties of hydrophobic/hydrophobised soil

\begin{tabular}{|c|c|c|c|c|c|c|c|c|c|c|c|c|c|c|}
\hline \multirow{3}{*}{ Reference } & \multirow{3}{*}{$\begin{array}{c}\text { Hydrophobic } \\
\text { agent }\end{array}$} & \multirow{3}{*}{$\begin{array}{l}\text { Hydrophobic } \\
\text { coating } \\
\text { produced }\end{array}$} & \multicolumn{4}{|c|}{ Shear strength } & \multicolumn{4}{|c|}{ Dilatancy } & \multicolumn{4}{|c|}{ Stiffness } \\
\hline & & & \multicolumn{2}{|c|}{ Glass beads } & \multicolumn{2}{|c|}{ Silica sand } & \multicolumn{2}{|c|}{ Glass beads } & \multicolumn{2}{|c|}{ Silica sand } & \multicolumn{2}{|c|}{ Glass beads } & \multicolumn{2}{|c|}{ Silica sand } \\
\hline & & & $S=0$ & $S \neq 0$ & $S=0$ & $S \neq 0$ & $S=0$ & $S \neq 0$ & $S=0$ & $S \neq 0$ & $S=0$ & $S \neq 0$ & $S=0$ & $S \neq 0$ \\
\hline [12] & \multirow{5}{*}{$\begin{array}{l}\mathrm{n}- \\
\text { octyltriethox } \\
\text { ysilane }\end{array}$} & \multirow{5}{*}{$\begin{array}{c}\text { Organosilane } \\
\left(\mathrm{Si}\left(\mathrm{OC}_{2} \mathrm{H}_{5}\right)_{2} \mathrm{C}\right. \\
\left.{ }_{8} \mathrm{H}_{17}\right)\end{array}$} & $\checkmark$ & $\checkmark$ & & & $\checkmark$ & $\checkmark$ & & & & & & \\
\hline [13] & & & $\checkmark$ & & & & & & & & & & & \\
\hline [14] & & & $\checkmark$ & $\checkmark$ & & & $\checkmark$ & $\checkmark$ & & & $\checkmark$ & $\checkmark$ & & \\
\hline$[15]$ & & & & & & & & & & & $\checkmark$ & $\checkmark$ & & \\
\hline [16] & & & & & $\checkmark$ & $\checkmark$ & & & $\checkmark$ & $\checkmark$ & & & & \\
\hline$[17]$ & Zycosil+ & Alklysiloxane & & & $\checkmark$ & $\checkmark$ & & & $\checkmark$ & $\checkmark$ & & & & \\
\hline [18] & & & & & & & & & & & & & $\checkmark$ & $\checkmark$ \\
\hline
\end{tabular}

\footnotetext{
Corresponding author: zzhoubo@connect.ust.hk
} 
examine the effectiveness of using a hydrophobised soil cover to reducing water infiltration in small-scale model slopes [4, 11]. [7] also measured the infiltration rate of hydrophobised soil for landfill cover applications.

Apart from the hydrological properties, mechanical behaviour of hydrophobised soil relevant to geotechnical engineering can be found from the literature (Table 1). In 2016, a review has been conducted to study the effects of hydrophobicity on water retention, infiltration and shear strength properties referenced to existing theories of unsaturated soil mechanics [5]. This study conducts an update of review, covering not only the shear strength properties, but also other crucial geotechnical properties including dilatancy, compressibility and stiffness. By reinterpreting some selected studies (Table 1), attempts are made to generalise the hydromechanical behaviour of artificially hydrophobised soil. Some further research is also proposed after the review.

\section{Effects of hydrophobisation on basic soil properties}

\subsection{Index properties}

Existing studies (e.g., [8, 19]) have demonstrated that the soil surface properties, after hydrophobisation, could be changed due to the formation of surface coating (e.g., PDMS when using DCDMS as the hydrophobic agent). Understanding how this surface coating would affect the soil index properties, such as particle size distribution, maximum and minimum void ratio and specific gravity $\left(G_{s}\right)$, are crucial in geotechnical engineering application. In existing literature, effects of hydrophobisation on $G_{s}$ has received some attention. $G_{s}$ of kaolin was found to be reduced as the concentration of the hydrophobic agent increased [7], whereas that of silica sand did not change much after treatment [20]. Based on the limited findings, it seems that whether the $G_{s}$ should decrease or remain unchanged depends on the soil type, the hydrophobic agent as well as the wetting agent used to measure the $G_{s}$ [21]. For the last factor, in particular, it was pointed out in ASTM standard D854 [22] that wetting agent, such as kerosene, is more appropriate than water for measuring the $G_{s}$ of a hydrophobic/hydrophobised sample [21]. Using water to wet this kind of soil does not guarantee full saturation (as a crucial requirement of accurate $G_{s}$ measurement) due to air entrapment [21].

Any effects of hydrophobisation on other soil index properties are currently missing in the literature.

\subsection{Degree of hydrophobicity}

Degree of hydrophobicity of a treated soil is normally quantified by two parameters, namely apparent contact angle (ACA) and water drop penetration time (WDPT) [5]. ACA is the angle between the apparent soil surface and tangential to the liquid-fluid interface [23]. Based on the ACA, soil can be classified as hydrophilic $\left(<45^{\circ}\right)$, hydrophobic $\left(>90^{\circ}\right)$ and somewhere in between $\left(45-90^{\circ}\right)$ [24]. WDPT is the time required for a water drop to penetrate through the soil surface. According to WDPT, soil can be classified as hydrophilic $(<5$ s), slightly hydrophobic $(5-60 \mathrm{~s})$, moderately hydrophobic $(61-$ 600 s), severely hydrophobic $(601-3600$ s) and extremely hydrophobic $(3601-18000 s)$ [25].

Most studies (except [26-28]) quantified the degree of hydrophobicity of treated soils under completely dry condition (e.g., [7, 29]). However, it was shown that the degree of hydrophobicity strongly depended on water content [26-28]. In general, the degree of hydrophobicity decreases with an increase in water content as there are more channels for water to flow through. This means that potentially a soil that has a high $S$, even after hydrophobisation, could be mistakenly described as hydrophobic. It is thus important to always report the degree of saturation $(S)$ of a hydrophobic/hydrophobised soil, together with the corresponding ACA and WDPT, when defining the degree of hydrophobicity.

\section{Effects of hydrophobisation on soil hydromechanical behaviour}

\subsection{Stress-strain relationships}

Based on the observations from the literature, the stressstrain relationships of untreated and treated soils (using n-octyltriethoxysilane and Zycosilt as the hydrophobic agent $[16,17])$ at dry and unsaturated conditions may be generalised as shown in Figure 1. For non-dilative soil, at dry condition, hydrophobisation reduces soil shear stress. Existing microscopic image analyses revealed that this kind of strength reduction could be because of the smoothening of the inter-particle friction due to the formation of hydrophobic coating after treatment [20]. Thought the strength reduction would become less prominent when the confining pressure increases [20].

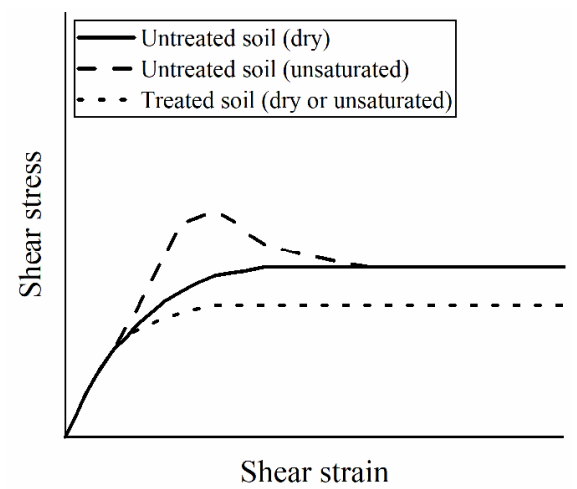

Fig. 1. Generalised stress-strain relationships of untreated and treated mineral soils at varying degrees of saturation.

At unsaturated condition, because of suction-induced dilatancy [30], untreated soil would normally exhibit a peak shear stress, followed by strain softening. Based on a laboratory study reported by [17], hydrophobisation switched the stress-strain behaviour from strain softening to strain hardening. This means that, apparently, the effects of suction-induced dilatancy vanished. Indeed, microscopic analysis of a hydrophobised soil suggested that water molecules appeared on the particle surface are convex [5]. This would cause ambiguities when defining 
matric (or capillary) suction (i.e., the difference between pore-air and pore-water pressure), and the contribution of 'suction' (if definable) to the strength of treated soil. [31] pointed out that the use of axis-translation technique for controlling suction of a hydrophobic/hydrophobised soil is inappropriate because this technique undesirably forces the convex menisci to be concave for maintaining pressure equilibrium between air and water.

As far as the authors are aware, there is the only one study that reports the stress-strain behaviour of hydrophobised soil of varying $S$, yet only one confining pressure $(50 \mathrm{kPa})$ was considered [17]. Clearly, more research is needed to characterise and improve the understanding of the stress-strain behaviour of hydrophobic/hydrophobised soils of varying $S$ levels and wider ranges of confining pressure. For slope application in particular, extra care is needed to study how hydrophobisation affects soil nonlinearity at low stress regimes (e.g., $<100 \mathrm{kPa}[32,33])$.

\subsection{Shear strength parameters}

Based on the stress-strain relationships available in the literature, the peak shear stress can be plotted against the corresponding vertical normal stress and the gradient of such plot can be determined as the peak friction angle, following the Mohr-Coulomb failure criterion (Fig. 2). In this study, two methods are used to reinterpret some selected studies from Table 1. The first method assumes the cohesion to be zero (i.e., forcing the linear fitted line to pass through the origin), while the second one does not. In general, hydrophobisation reduces the friction angle by $2-16^{\circ}$, depending on the soil type, the hydrophobic agent and the amount of $S$ considered. The reduction of peak friction angle is again attributed to the smoothening effects by the hydrophobic coatings on soil surface. It is interesting to reveal that for the case of glass beads, the reduction of peak friction angle is much more significant when the beads are in unsaturated state (by $10^{\circ}$ ) than in the dry state (by $3^{\circ}$ ). Unfortunately, in existing literature, there is only one set of data that illustrates how hydrophobisation affects the peak friction angle of unsaturated glass beads ([12] and [14]; refer to Table 1). No data is available for mineral soil, however.

For dry, untreated clean sand and glass beads, no cohesion is expected, so it is reasonable to set cohesion to be zero when determining the friction angle. When they are unsaturated, (apparent) cohesion exists because of matric suction. For dry, treated sand and glass beads, on the other hand, previous studies ([34] and [35]) have reported that the some hydrophobic coatings such as PDMS would induce soil adhesion, yet its effects on cohesion is unknown. Thus, it may be not appropriate to always assume the cohesion of treated soil to be zero. From Fig. 2, presuming cohesion to be zero in treated soil would tend to (not always) overestimate the peak friction angle. Nonetheless, it is worth mentioning that the method of determining the peak friction angle, whether presuming the cohesion to be zero or not, follows a simple linear Mohr-Coulomb failure envelope. Any soil nonlinearity exhibited in low stress regimes is ignored. Any cohesion obtained from a best-fitted linear envelop should be treated with caution. More study is needed to quantify how the adhesion induced by hydrophobisation might affect the soil cohesion.

So far, there is only one study to determine the critical state of hydrophobised sand [20]. This unique study revealed a reduction of the critical-state friction angle from $29.9^{\circ}$ to $27.1^{\circ}$ after hydrophobisation by DMDCS.

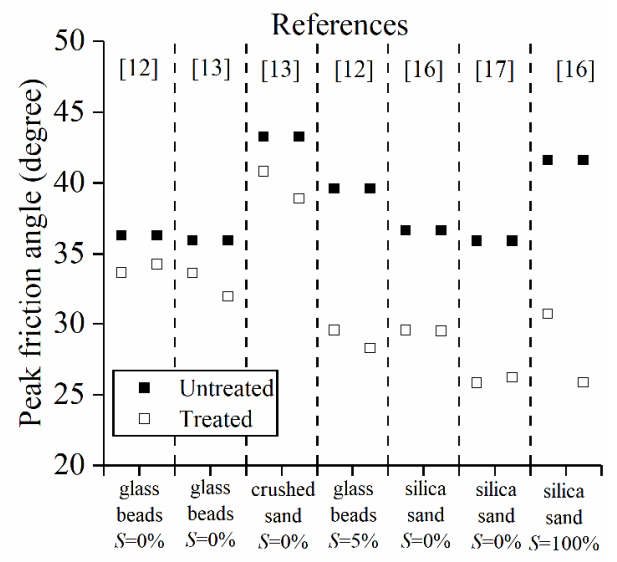

Soil type and degree of saturation

Fig. 2. Peak friction angles of untreated and treated soils at different values of $S$, calculated based on the reported data from the literature in Table 1 . In each reference, the friction angle was determined by assuming cohesion to be zero (the data on the left side) or non-zero (the data on the right side).

\subsection{Dilatancy}

Based on the relationships between vertical displacement and horizontal displacement obtained from a direct-shear box test, the dilation angle mobilised during the shearing process is determined in this study. Fig. 3 shows the dilatancy of dry glass beads by analysing the shear test data reported by [12, 14]. Both untreated and treated glass beads showed dilative behaviour, while the treated case appears to require more horizontal displacement to mobilise the peak dilation angle. The observation from glass beads is, however, not consistent with the findings from mineral soil, probably due to different hydrophobic agents used (Fig. 4, silica sand in this case [16, 17]). At both low (Fig. 4(a)) and high (Fig. 4(b)) stress regimes, hydrophobisation made the dilation vanished. As expected, at low stress regime, soil dilatancy was more prominent than that at high stress regime. It is thus not surprising to see a greater drop of the peak dilation angle at the low stress regime (by $13^{\circ}$; compared to $2^{\circ}$ at high stress case). The underlying reason of the observed different dilatancy behaviour is unclear and needs further investigation.

The dilation angles of both treated and untreated sand derived from [17] is shown in Fig. 5. As expected, before treatment, the unsaturated sand exhibited slightly greater dilatancy than the dry case because of suction hardening. After hydrophobisation by Zycosilt, the sand was more contractive at the beginning of shearing and much less dilative at large shear displacements. The reduction of dilation angle for the unsaturated treated sand $\left(12^{\circ}\right)$ was more significant. This finding, however, 
was made at one $S$ and one confining pressure. Because of the lack of data, it is not able yet to generalise the observation for wider ranges of confining pressures and $S$. The underlying mechanism(s) causing the behavioural change due to hydrophobisation is/are unclear.

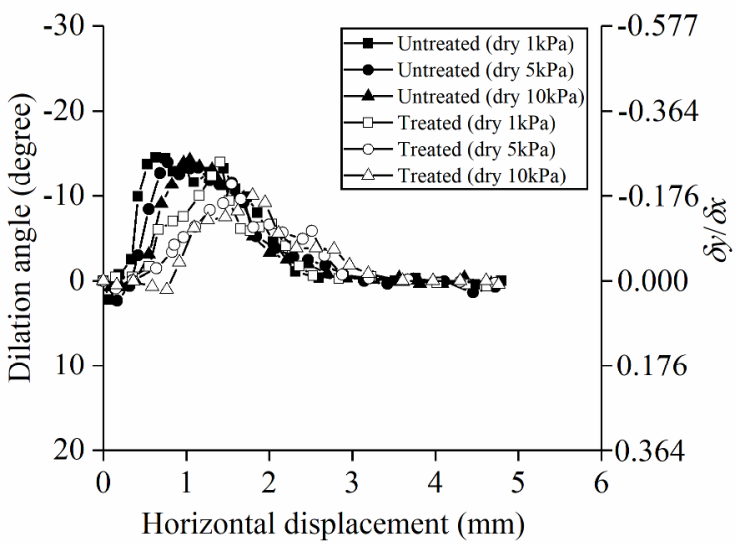

Fig. 3. Mobilisation of dilatancy angle of dry untreated and treated glass beads during shearing, calculated based on the data from $[12,14] . \delta y$ and $\delta x$ are the vertical and horizontal displacements, respectively. Negative value means dilation.
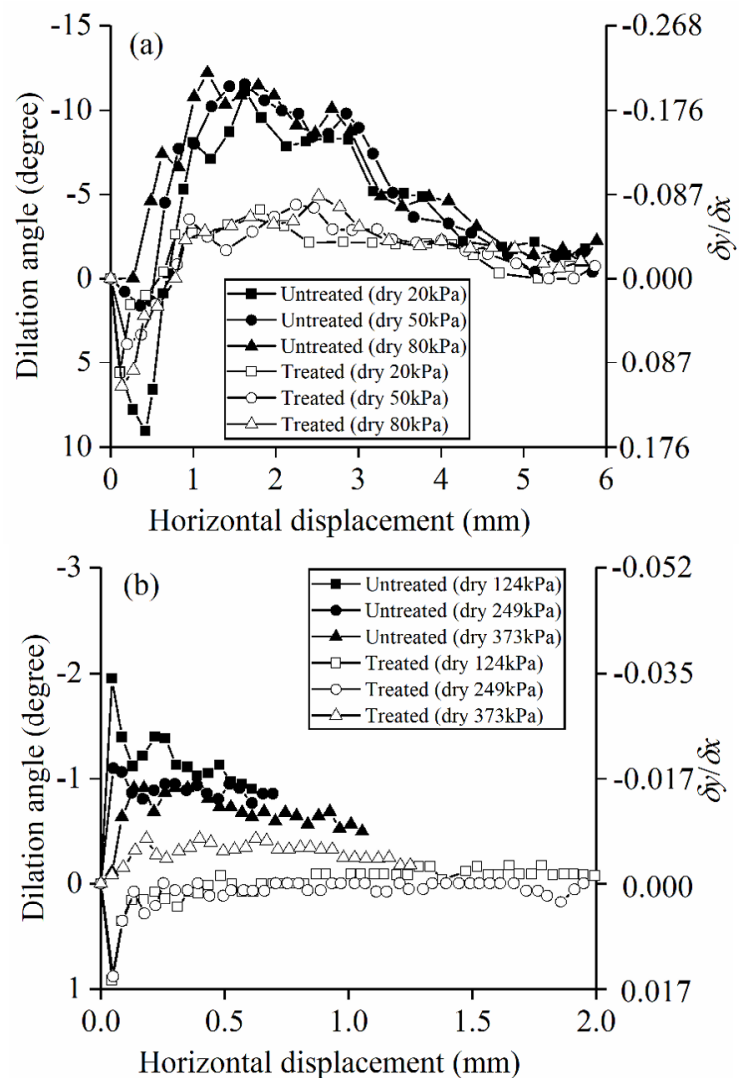

Fig. 4. Mobilisation of dilatancy angle of untreated and treated silica sands during shearing, calculated based on the data from $[16,17])$, at (a) low stress levels $(<100 \mathrm{kPa})$; and (b) high stress levels $(>100 \mathrm{kPa})$..

\subsection{Compressibility}

Regarding of soil compressibility, there is only one study that shows how hydrophobisation affects the criticalstate line (CSL) in an $e-\log p$ ' space (where $e$ is void ratio and $p$ ' is mean effective stress) [20]. They found that the CSLs of untreated and DMDCS-treated sand have the same shape, but the CSL of the treated sand was at a position lower than that of the untreated sand. It is also interesting to note from their study that the chemical concentration added to hydrophobise the sand has an evident effect on the position of the CSL. The higher the concentration, the lower the position of the CSL would be. As higher chemical concentration results in a thicker hydrophobic coating, the difference of CSLs between untreated and treated case becomes bigger.

Because of the lack of data, how hydrophobisation may affect the compressibility and swelling indices of a soil, both dry and unsaturated, is unknown.

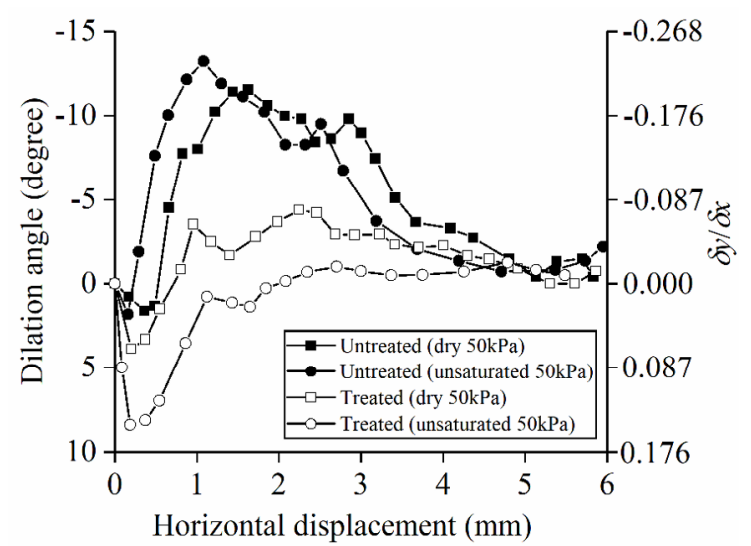

Fig. 5. Mobilisation of dilatancy angle of untreated and treated silica sands during shearing, calculated based on the data from [17], at dry and unsaturated conditions.

\subsection{Stiffness}

In the literature, bender elements have been used to determine the shear wave velocity of both untreated and treated glass beads [14]. By knowing the bulk density (given in [14]), the maximum shear modulus $\left(G_{\max }\right)$ is determined in this study. In Fig. 6(a), as expected, an increase in confining pressure led to an increase in $G_{\max }$ of both untreated and treated glass beads at any $S$. At dry condition, both untreated and treated glass beads have similar $G_{\max }$ at the confining pressure of $1 \mathrm{kPa}$, but the treated glass beads became stiffer at a higher confining pressure of $20 \mathrm{kPa}$. This was explained that although all specimens were prepared at the same initial $e$, the treated glass beads were more compressible than the untreated one (though compressive curve (i.e., $e-\log p^{\prime}$ curve) is not provided) after applying a confining pressure [14]. The treated case was thus denser and has a higher stiffness.

However, at unsaturated condition, it is interesting to observe that at low confining pressure $(<5 \mathrm{kPa})$, the untreated glass beads were stiffer than the treated case, but it was reversed when a higher confining pressure of 5 $\mathrm{kPa}$ was applied. The switch of behaviour may be caused by the combined effects of suction and compressibility [14]. As mentioned in Section 3.1, it is ambiguous to define matric suction for treated soil due to the convex shape of water meniscus. If it can be hypothesised that capillary effects are made vanished by hydrophobisation, this could then explain why the treated glass beads have a lower stiffness than the untreated case where suction 
exists. At relatively high confinement (e.g., $5 \mathrm{kPa}$ ), the treated glass beads were more compressible than the untreated case [14], resulting in a denser packing and hence a higher stiffness, even suction was disappeared. The underlying mechanism(s) of causing the switch of the behaviour due to the combined effects of confining pressure and the 'loss' (by hydrophobisation) of matric suction is/are unclear. Nonetheless, it seems that knowing the change in soil compressibility by hydrophobisation is crucial for understanding the stiffness behaviour.
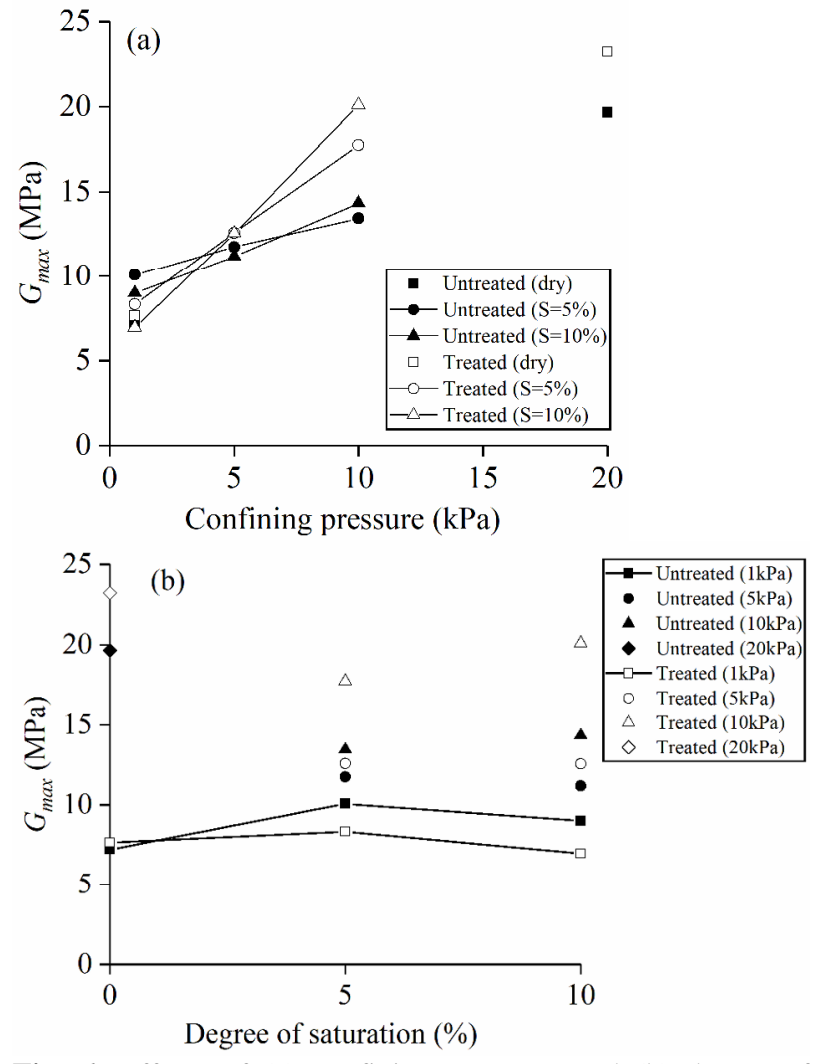

Fig. 6. Effects of (a) confining pressure; and (b) degree of saturation on the maximum shear modulus of untreated and treated glass beads, calculated based on the shear wave velocity data from [14]. Note that a trend line is provided only when there are more than three data points in a data series.

The data of $G_{\max }$ from the same study is related with $S$ in Fig. 6(b). Unfortunately, due to the lack of data, no clear trend can be observed or generalised. The $G_{\text {max }}$ can be increased or decreased as $S$ increases.

Effects of $S$ on $G_{\max }$ of untreated and treated glass beads were also studied by [15]. A clearer trend can be identified (not shown in the present paper). Consistent with the theories of unsaturated soil mechanics, the $G_{\max }$ of untreated glass beads increased as they were drier (i.e., reduction of $S$ ), and it peaked at $S=5 \%$. Beyond this, the $G_{\max }$ dropped abruptly to the lowest value at $S=$ $0 \%$. On the contrary, the $G_{\max }$ of the treated glass beads was independent of $S$ and it remained almost constant at a value very similar to the value obtained from dry untreated case. This implies that the capillary effects and associated suction (as existed in untreated case) may have made disappeared by hydrophobisation.
Apart from glass beads, shear wave velocity measured from treated and untreated silica sand is reported by [18]. Similarly, the published data are reinterpreted in this study to relate $G_{\max }$ with confining pressure and $S$ (Fig. 7). As can be seen in Fig. 7(a), the $G_{\max }$ of treated silica sand at the confining pressure of 50 $\mathrm{kPa}$ was stiffer than that of the untreated case. Again, the compaction curves of the sand before and after hydrophobisation are not available for more in-depth interpretation (i.e., unsure whether the observed higher stiffness of the treated case was because of the greater compressibility).
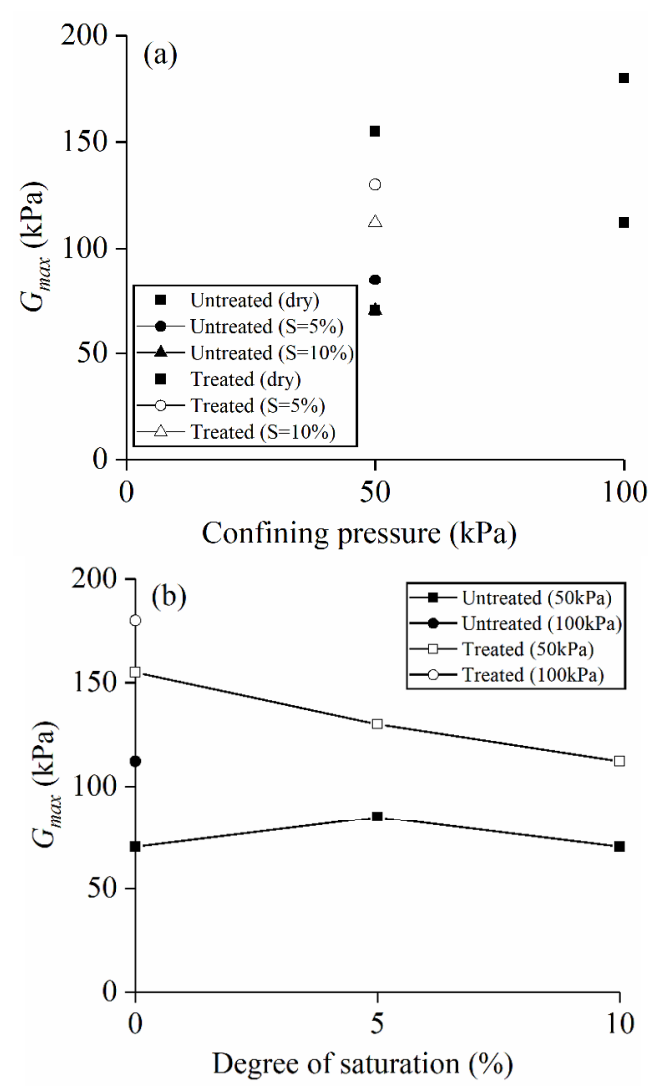

Fig. 7. Effects of (a) confining pressure; and (b) degree of saturation on the maximum shear modulus of untreated and treated silica sand, reinterpreted based on the data from [18]. Note that a trend line is provided only when there are more than three data points in a data series.

Attempts were also made to relate the $G_{\max }$ with $S$ in Fig. 7(b). Because of the limited data available from the study and also from the literature, it is difficult to identify any plausible trend.

\section{Future work}

Based on the literature review and some reinterpretation of data from existing studies, some research gaps may be identified for future work:

1. Due to the formation of a hydrophobic coating onto the soil particle surface after hydrophobisation, it is important to quantify how this chemical process and the surface modification would affect the basic soil index properties. While the hydrophobisation effects 
on the soil specific gravity has received some recent attention, how they modify particle-size distribution, maximum and minimum void ratio and specific gravity are currently unknown.

2. Degree of hydrophobicity of a soil, as indicated by apparent contact angle or/and water drop penetration time, is normally defined at a fully dry condition. How water content or degree of saturation of a hydrophobised soil may affect the definition of the soil's degree of hydrophobicity is unclear.

3. In terms of shear behaviour, it is currently unknown how a hydrophobised soil, both dry or unsaturated, would behave at a low-stress regime (say, less than $100 \mathrm{kPa}$ ), given the fact that in slope applications, hydrophobised soil is normally applied at relatively superficial depths where the overburden pressure is low. Moreover, how the formation of hydrophobic coating would affect the soil cohesion (or/and friction angle) has not adequately investigated.

4. In terms of soil dilatancy, it is a general observation that hydrophobisation makes the dilatancy of a fully dry soil vanished. The stress-dilatancy behaviour of unsaturated treated soil is missing in the literature.

5. In terms of soil compressibility, there is only one study that reports a possible shift of the critical-state line in $e$ - $\log p$ ' space due to hydrophobisation by DMDCS. How the treatment causes changes in the compressibility and swelling indices of both dry and unsaturated soil is not available from the literature.

6. In terms of stiffness, there are only a few studies (< 5) available in the literature, and the data is limited to gain adequate understanding on the effects of hydrophobisation on stiffness. Nonetheless, from the reinterpretation, it seems that knowing any changes of soil compressibility due to hydrophobisation is one of the keys to help and understand the combined effects of confining pressure and matric suction (or degree of saturation) on stiffness behaviour.

It is important to emphasise that in this review, only the behaviour of artificially-hydrophobised granular matters (i.e., silica sand or glass beads) are discussed, because of the limited datasets available in the literature (Table 1). Clearly, soil texture (hence surface chemistry), choice of hydrophobic agents and treatment conditions adopted (e.g., temperature) would directly affect the properties of the hydrophobic coating formed, and hence the contact properties of the treated soil. Cautions should be taken before attempting to generalise the behavioural changes due to hydrophobisation, as observed from this review.

\section{Acknowledgements}

The authors acknowledge the financial support from the General Research Fund (GRF) \#16212818 funded by the Hong Kong Research Grant Council.

\section{References}

1. S. H. Doerr, R. A. Shakesby and R. P. D. Walsh. EarthScience Reviews, 51, 33-65 (2000).

2. L. F. DeBano. J Hydrol, 231, 195-206 (2000).
3. L. F. DeBano. J Hydrol, 231, 4-32 (2000).

4. S. Zheng, S. D. N. Lourenco, P. J. Cleall, T. F. M. Chui, A. K. Y. Ng and S. W. Millis. J Hydrol, 554, 582-599 (2017).

5. C. Beckett, A. Fourie and D. Toll. 3rd Eur. Conf. on Unsaturated Soils, 9, 11011 (2016).

6. S. H. Y. Ng and S. D. N. Lourenco. Geotechnique, 66, 441-444 (2016).

7. Y. Choi, H. Choo, T. S. Yun, C. Lee and W. Lee. Materials (Basel, Switzerland), 9, 978 (2016).

8. L. F. Orozco and B. Caicedo. Géotechnique Letters, 7, 1823 (2017).

9. H. Czachor, S. H. Doerr and L. Lichner. J Hydrol, 380, 104-111 (2010).

10. Z. Wang, Q. J. Wu, L. Wu, C. J. Ritsema, L. W. Dekker and J. Feyen. J Hydrol, 231, 265-276 (2000).

11. S. Zheng, S. D. N. Lourenco, P. J. Cleall, S. W. Millis, A. K. Y. Ng and T. F. M. Chui. 4th World Landslide Forum, 3, 523-528 (2017).

12. Y.-H. Byun, V. M. H. Jose, T. S. Yun and J.-S. Lee. GeoCongress 2012, 4358-4365 (2012).

13. Y. H. Byun and J. S. Lee. The 2012 World Congress on ACEM, (2012).

14. Y. H. Byun, M. K. Tran, T. S. Yun and J. S. Lee. Geotech Test J, 35, 193-200 (2012).

15. Q. H. Truong, J. S. Lee, Y. Dong and T. S. Yun. Soils Found, 51, 713-721 (2011).

16. M. Z. Karim, S. E. Tucker-Kulesza and M. M. Derby. IFCEE 2018, 75-83 (2018).

17. B. S. Kim, Y. Takeshita, S. Kato and S. W. Park. 6th Int. Conf. on Unsaturated Soils, 1, 159-165 (2014).

18. D. Kim, T. Yun, C. Lee and J. Lee. the 5th Asia-Pacific Conf. on Unsaturated Soils, 1, 629-633 (2011).

19. D. Kim, H. J. Yang, T. S. Yun, B. Kim, S. Kato and S. W. Park. the 18th Int. Conf. on Soil Mechanics and Geotech. Eng., 361-364 (2013).

20. D. Liu, S. D. N. Lourenço and J. Yang. Geotechnique, $\mathbf{0}$, 1-6 (2018).

21. D. Liu, S. D. N. Lourenço, J. Yang, Z. Zhou and A. K. Leung. Geotechnique, 0, 1-3 (2019).

22. ASTM. D854-14, (2014).

23. G. Wolansky and A. Marmur. Colloid Surface A, 156, 381-388 (1999).

24. ASTM. D7334-08, (2008).

25. E. B. A. Bisdom, L. W. Dekker and J. F. T. Schoute. Geoderma, 56, 105-118 (1993).

26. H. Liu, Z. Q. Ju, J. Bachmann, R. Horton and T. S. Ren. Soil Sci. Soc. Am. J., 76, 342-349 (2012).

27. S. D. N. Lourenco, N. Jones, C. Morley, S. H. Doerr and R. Bryant. Vadose Zone J., 14, 8 (2015).

28. Y. Li, X. F. Wang, Z. K. Cao and B. C. Si. Can J Soil Sci, 97, 226-240 (2017).

29. C. Lee, H. J. Yang, T. S. Yun, Y. Choi and S. Yang. Vadose Zone J., 14, (2015).

30. S. K. Vanapalli, D. G. Fredlund, D. E. Pufahl and A. W. Clifton. Canadian Geotechnical Journal, 33, 379-392 (1996).

31. C. T. S. Beckett, D. G. Toll, A. B. Fourie and P. R. Ward. 7th Int. Conf. on Unsaturated Soils, 2, 1249 (2018).

32. M. Maksimovic. Journal of Geotechnical Engineering, 115, 581-586 (1989).

33. T. Chakraborty and R. Salgado. J. Geotech. Geoenviron. Eng., 136, 527-532 (2010).

34. J. Yu, S. Chary, S. Das, J. Tamelier, K. L. Turner and J. N. Israelachvili. Langmuir, 28, 11527-34 (2012).

35. D. Liu, C. S. Sandeep, K. Senetakis, V. Nardelli and S. D. N. Lourenço. Powder Technology, 347, 76-84 (2019). 